\title{
Applicability of source scaling relations for crustal earthquakes to estimation of the ground motions of the 2016 Kumamoto earthquake
}

Kojiro Irikura ${ }^{1^{*}} \mathbb{D}$, Ken Miyakoshi ${ }^{2}$, Katsuhiro Kamae ${ }^{3}$, Kunikazu Yoshida $^{2}$, Kazuhiro Somei ${ }^{2}$, Susumu Kurahashi ${ }^{4}$ and Hiroe Miyake ${ }^{5}$

\begin{abstract}
A two-stage scaling relationship of the source parameters for crustal earthquakes in Japan has previously been constructed, in which source parameters obtained from the results of waveform inversion of strong motion data are combined with parameters estimated based on geological and geomorphological surveys. A three-stage scaling relationship was subsequently developed to extend scaling to crustal earthquakes with magnitudes greater than $M_{w}$ 7.4. The effectiveness of these scaling relationships was then examined based on the results of waveform inversion of 18 recent crustal earthquakes $\left(M_{w} 5.4-6.9\right)$ that occurred in Japan since the 1995 Hyogo-ken Nanbu earthquake. The 2016 Kumamoto earthquake, with $M_{w} 7.0$, was one of the largest earthquakes to occur since dense and accurate strong motion observation networks, such as K-NET and KiK-net, were deployed after the 1995 Hyogo-ken Nanbu earthquake. We examined the applicability of the scaling relationships of the source parameters of crustal earthquakes in Japan to the 2016 Kumamoto earthquake. The rupture area and asperity area were determined based on slip distributions obtained from waveform inversion of the 2016 Kumamoto earthquake observations. We found that the relationship between the rupture area and the seismic moment for the 2016 Kumamoto earthquake follows the second-stage scaling within one standard deviation $(\sigma=0.14)$. The ratio of the asperity area to the rupture area for the 2016 Kumamoto earthquake is nearly the same as ratios previously obtained for crustal earthquakes. Furthermore, we simulated the ground motions of this earthquake using a characterized source model consisting of strong motion generation areas (SMGAs) based on the empirical Green's function (EGF) method. The locations and areas of the SMGAs were determined through comparison between the synthetic ground motions and observed motions. The sizes of the SMGAs were nearly coincident with the asperities with large slip. The synthetic ground motions obtained using the EGF method agree well with the observed motions in terms of acceleration, velocity, and displacement within the frequency range of $0.3-10 \mathrm{~Hz}$. These findings indicate that the 2016 Kumamoto earthquake is a standard event that follows the scaling relationship of crustal earthquakes in Japan.
\end{abstract}

Keywords: Scaling relationship, Crustal earthquake, Source model, Strong ground motion prediction, Characterized source model, Strong motion generation area

\footnotetext{
*Correspondence: irikura@geor.or.jp

1 Disaster Prevention Research Center, Aichi Institute of Technology, 1247

Yachigusa, Yakusa-cho, Toyota 470-0392, Aichi, Japan

Full list of author information is available at the end of the article
} 


\section{Background}

One of the most important factors when predicting strong ground motions is the characterization of source models for future earthquakes. Fundamental information for the source model comes from source scaling relationships, which control the fault parameters necessary to estimate ground motions. Conventionally, scaling relationships (e.g., Kanamori and Anderson 1975) have been evaluated based on the fault length and fault slip, which are primarily determined geologically from surface offsets, and on the rupture area, which is determined seismologically from the aftershock distribution. The seismic moments of large earthquakes are estimated primarily from teleseismic data, although they are sometimes inferred from geodetic data. Catalogs of source parameters include a variety of qualities, some of which are not always available for strong motion estimation (e.g., Wells and Coppersmith 1994; Stirling et al. 2002, 2013). To predict near-source strong motions dominated by shortperiod motions of $<1 \mathrm{~s}$, which are of particular interest to engineers, we must carefully assess whether conventional scaling relationships are applicable.

Irikura and Miyake (2001) proposed a two-stage scaling relationship of source parameters for crustal earthquakes in Japan, which combined source parameters obtained from the waveform inversion of strong-motion data (Somerville et al. 1999; Miyakoshi et al. 2000) with those obtained from geological and geomorphological surveys, selecting only reliable data from the source parameter catalog compiled by Wells and Coppersmith (1994). They found that there is a strong correlation between source parameters from the waveform inversion results and those from geological and geomorphological data for crustal earthquakes of magnitudes larger than 7 .

Accumulated strong ground motion data provide us with crucial information concerning the rupture processes of earthquakes and wave propagation for simulating ground motions during large earthquakes. The scaling relationships of the fault parameters from the waveform inversion results for the source processes based on strong-motion data provide a clue as to how to solve this problem.

A three-stage scaling model of the source parameters for crustal earthquakes in Japan has been constructed by Irikura and Miyake (2001) and Murotani et al. (2015). Miyakoshi et al. (2015) examined the effectiveness of these scaling relationships using the waveform inversion results of 18 crustal earthquakes $\left(M_{w} 5.4-6.9\right)$ that occurred in Japan between the 1995 Hyogo-ken Nanbu earthquake and 2015. The maximum $M_{w}$ of the crustal earthquakes whose slip distributions were determined by these workers from waveform inversion was 6.9, i.e., the 1995 Hyogo-ken Nanbu earthquake itself.
The 2016 Kumamoto earthquake with $M_{w} 7.0$ was one of the largest earthquakes since the 1995 Hyogo-ken Nanbu earthquake. Strong ground motions from this earthquake were recorded by dense and accurate strongmotion networks such as Kyoshin Net (K-NET) and Kiban-Kyoshin Net (KiK-net) of the National Research Institute for Earth Science and Disaster Resilience (NIED) and the Seismic Intensity Meters Network of the Japan Metrological Agency (JMA).

We collected slip distributions inverted by the strongmotion data of the 2016 Kumamoto earthquake and extracted the rupture and asperity areas from the waveform inversion results. Then, we examined whether the relationships between the rupture area and seismic moment and between the asperity area and rupture area followed the scaling relationships of the known source parameters for Japan. We investigated whether these relationships were useful for reproducing the strong ground motions of the 2016 Kumamoto earthquake. In addition, we constructed a characterized source model with the SMGAs based on the slip distribution model. We will discuss the validity of the simulations of strong ground motions using the SMGA source model and compare these results to observations of strong ground motions recorded near the source fault of the 2016 Kumamoto earthquake.

\section{Scaling relationships}

The three-stage scaling relationship has two bending points. The first bending of the scaling relationship for the rupture area $S$ and the seismic moment $M_{0}$ exists at approximately $M_{0}=7.5 \times 10^{18} \mathrm{~N} \mathrm{~m}$, i.e., $M_{w} 6.5$, because of the thickness of the seismogenic zone. In the first stage, $S$ is proportional to $M_{0}^{2 / 3}$, and in the second stage it is proportional to $M_{0}^{1 / 2}$, as initially indicated by Shimazaki (1986). Murotani et al. (2015) assumed that a second bending at about $M_{0}=1.8 \times 10^{20}(\mathrm{~N} \mathrm{~m})$, i.e., $M_{w} 7.4$, was caused by the saturation of the slip on the fault plane. In the third stage, $S$ is proportional to $M_{0}$ for $M_{0}>1.8 \times 10^{20}(\mathrm{~N} \mathrm{~m})$.

The scaling relationship can be summarized as follows.

The first scaling relationship between the source area $S$ and the seismic moment $M_{0}$ is expressed as

$$
\begin{aligned}
& S\left(\mathrm{~km}^{2}\right)=2.23 \times 10^{-15} \times\left(M_{0} \times 10^{7}\right)^{2 / 3} \text { for } \\
& M_{0}<7.5 \times 10^{18}(\mathrm{~N} \mathrm{~m}),
\end{aligned}
$$

the second is expressed as

$$
\begin{aligned}
& S\left(\mathrm{~km}^{2}\right)=4.24 \times 10^{-11} \times\left(M_{0} \times 10^{7}\right)^{1 / 2} \text { for } 7.5 \times 10^{18} \\
& (\mathrm{~N} \mathrm{~m})<M_{0} \leq 1.8 \times 10^{20}(\mathrm{~N} \mathrm{~m}),
\end{aligned}
$$

and the third is expressed as

$$
S\left(\mathrm{~km}^{2}\right)=1.0 \times 10^{-17} \times M_{0} \text { for } M_{0}>1.8 \times 10^{20}(\mathrm{~N} \mathrm{~m}) .
$$


Strong-motion data from the 2016 Kumamoto earthquake were recorded by K-NET and KiK-net. This event had a maximum seismic intensity of 7 , was observed at several stations near the source, and caused widespread damage across Kumamoto Prefecture. High acceleration values were observed, such as $1791 \mathrm{~cm} / \mathrm{s}^{2}$ (synthesis of the three components) at the municipal observatory of Ohzu and $1362 \mathrm{~cm} / \mathrm{s}^{2}$ at KMMH16 (KiK-net Mashiki).

Slip distributions obtained from waveform inversion of the strong-motion data from this event have previously been published (e.g., Asano and Iwata 2016; Kubo et al. 2016; Yoshida et al. 2016). Kubo et al. (2016) performed waveform inversion with strong-motion data from $27 \mathrm{sta}-$ tions of K-NET, KiK-net, and F-net based on an assumed single fault plane with a strike of $226^{\circ}$ and a dip of $65^{\circ}$ and a fault area $56 \mathrm{~km}$ in length and $24 \mathrm{~km}$ in width. The assumed fault plane is consistent with the geometry and location of the Futagawa fault zone (Headquarters for Earthquake Research Promotion 2016). Asano and Iwata (2016) used strong-motion data from 15 stations of K-NET, KiK-net, and F-net and assumed a fault model with two segments along the Futagawa and Hinagu fault zones.
Yoshida et al. (2016) used strong-motion data from 22 stations of K-NET and KiK-net, and an assumed fault model with four fault segments of different strikes and dips: one (Seg. 1) along the Hinagu fault zone, another (Seg. 2) along a plane connecting the Futagawa and Hinagu fault zones, and two more (Seg. 3 and Seg. 4) along the Futagawa fault zone, as shown in Fig. 1a. A map view of the aftershock distribution within $48 \mathrm{~h}$ after the 2016 Kumamoto earthquake is also shown in Fig. 1a. Yoshida et al. (2016) conducted a two-step approach for multiple time-window kinematic waveform inversions of strong-motion data to estimate detailed slip distributions on these four fault segments. First, the slip distribution was inverted using $0.05-0.5 \mathrm{~Hz}$ band-pass filtered strongmotion data, as shown in Fig. 1b. The rupture area of the earthquake was estimated using the trimming criterion of Somerville et al. (1999) with the slip model from the waveform inversion. The trimming results remove two columns of the segment at the southwestern edge (Seg. 1 ), which reduces the rupture area and seismic moment by $10 \%$ and $3 \%$, respectively. Secondly, the slip distribution was reanalyzed based on the $0.05-1.0 \mathrm{~Hz}$ waveform inversion of the strong-motion data for this reduced

\section{a Fault model}

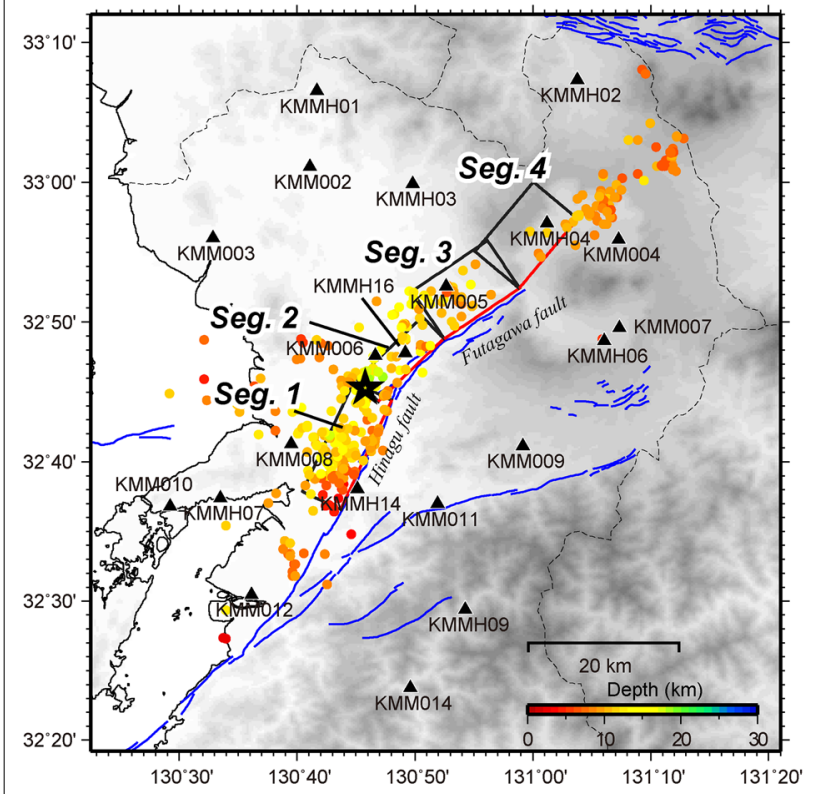

\section{b Total slip for $0.05-0.5 \mathrm{~Hz}$}

$\mathrm{NE} \underset{65^{\circ}}{\longleftarrow}$
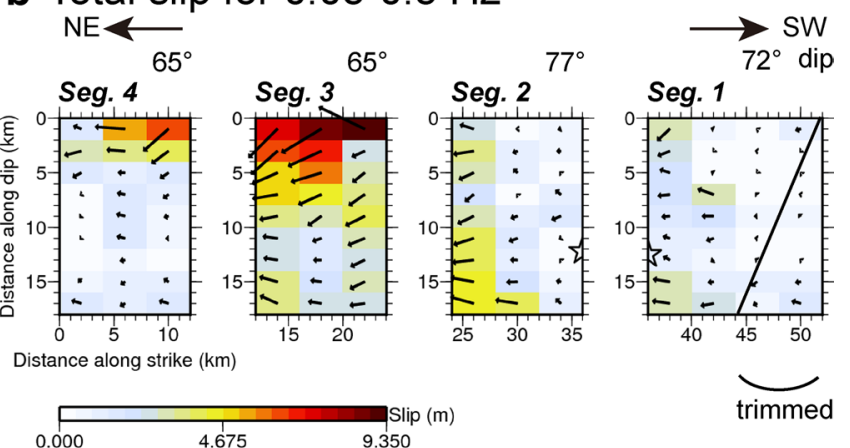

\section{c Total slip for $0.05-1.0 \mathrm{~Hz}$}

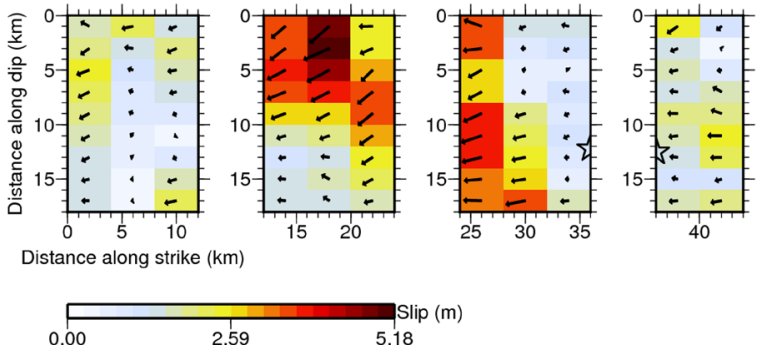

Fig. 1 Map view of the 2016 Kumamoto earthquake and the distribution of total slip. a Map showing the locations of the four fault segments of the source fault model (four rectangles), the observational stations (black triangles) and the aftershocks (circles) that occurred within $48 \mathrm{~h}$ of the mainshock, as reported in the JMA unified hypocenter catalog. The star indicates the starting point of the mainshock rupture. The blue lines indicate the locations of active faults (National Institute of Advanced Industrial Science and Technology). b Total slip distribution based on the $0.05-0.5 \mathrm{~Hz}$ strong-motion waveform inversion of Yoshida et al. (2016). The entire rupture area was trimmed following the criteria defined by Somerville et al. (1999). c Total slip distribution based on the $0.05-1.0 \mathrm{~Hz}$ strong-motion waveform inversion (Yoshida et al. 2016) 
fault plane, as shown in Fig. 1c. For this inversion analysis, more detailed time windows were used with shorter durations and larger numbers of windows to maintain the total window length at each subfault. The rupture area from the $0.05-1.0 \mathrm{~Hz}$ waveform inversion remains unchanged after trimming. The "true" rupture area and seismic moment after the two-step waveform inversion performed by Yoshida et al. (2016) are shown in Table 1.

We have also collected slip models inverted by other authors (Asano and Iwata 2016; Kubo et al. 2016). Rupture areas were estimated based on the criteria of Somerville et al. (1999). The source parameters from the results of all three inversions are compiled in Table 1. The estimated values of the seismic moment vary from study to study because the methods and data used for the inversion analyses differ. The seismic moment was also determined using a long-period full-wave inversion analysis of broadband F-net data (Fukuyama et al. 1998). In past evaluation of the scaling relationships of crustal earthquakes (Miyakoshi et al. 2015), seismic moments obtained from the long-period, full-wave data from the F-net were found to be more stable than those from the inversion of strong-motion data. Therefore, to be consistent with the previous study, we adopted the F-net seismic moment and a logarithmic average of the rupture areas of the three models for the scaling relationship of seismic moment versus rupture area.

The relationship between the rupture area $S$ and the seismic moment $M_{0}$ for the 2016 Kumamoto earthquake with $M_{w} 7.0$ was added to the scaling relationships confirmed by Miyakoshi et al. (2015) shown in Fig. 2. Without the 2016 Kumamoto earthquake, the standard deviation of the second stage was calculated to be $\sigma=0.14$. The relationship of $S$ versus $M_{0}$ for this event follows the second-stage scaling within one standard deviation. We also found that the relationships for individual models are within one standard deviation.

Next, we examined the relationship between the average slip $D$ and the seismic moment $M_{0}$ for inland crustal earthquakes. The average slip $D$ on the source fault for each model was estimated from the heterogeneous slip distributions of the waveform inversion results. The average slip of $1.66 \mathrm{~m}$ reported in Table 1 is the logarithmic average of the average slips from the three models (Asano and Iwata 2016; Kubo et al. 2016; Yoshida et al. 2016). The seismic moment from F-net was adopted. Then, the relationship of $D$ versus $M_{0}$ for the 2016 Kumamoto earthquake was plotted with the corresponding scaling relationship of Miyakoshi et al. (2015) in Fig. 3. In the second stage, $D$ increased proportionally with $M_{0}^{1 / 2}$, that is, $D$ versus $M_{0}$ for this event nearly coincides with the second-stage scaling. The relationships between $D$ and $M_{0}$ for individual models are also plotted in Fig. 3.

For strong motion estimation, another scaling relationship between the rupture area $S$ and the asperity area $S_{\text {a }}$ plays an important role. It has been confirmed by Irikura and Miyake (2001) and Miyakoshi et al. (2015) that an asperity area with a large slip increases proportionally in area with the entire rupture area. The asperity area was determined following the procedure of Somerville et al. (1999) based on the inverted heterogeneous slip distributions. The asperity area is $160 \mathrm{~km}^{2}$, which is about $20 \%$ of the trimmed fault area of Yoshida et al. (2016). The logarithmic average of the asperity areas of the three models is $178 \mathrm{~km}^{2}$. The combined asperity area $S_{a}$ scales with the seismic moment $M_{0}$, as shown in Fig. 4, which includes the results for the 2016 Kumamoto earthquake.

\section{Strong motion generation area (SMGA) model for simulating strong ground motions of the 2016 Kumamoto earthquake}

Strong ground motions are more closely related to regions of slip heterogeneity rather than the entire rupture area and total seismic moment (Irikura and Miyake 2011). Therefore, a characterized source model was proposed that consisted of one or several asperities with large slips and a background area with less slip (Miyake et al. 2003) based on source characterizations defined using slip distributions from the waveform inversion of strong-motion data.

Table 1 Source parameters of the $\mathbf{2 0 1 6}$ Kumamoto earthquake obtained from inversion results

\begin{tabular}{|c|c|c|c|c|c|c|c|c|c|c|c|c|c|c|c|c|}
\hline \multirow[t]{2}{*}{ References } & \multirow{2}{*}{$\begin{array}{l}\text { Mo (inv.) } \\
\text { N m }\end{array}$} & \multirow{2}{*}{$\begin{array}{l}\text { Mo (F-net) } \\
\mathrm{N} \mathrm{m}\end{array}$} & \multicolumn{2}{|c|}{ Length } & \multicolumn{2}{|c|}{ Width } & \multicolumn{2}{|c|}{ Rupture area } & \multicolumn{2}{|c|}{ Av. slip } & \multicolumn{2}{|c|}{ Max. slip } & \multicolumn{4}{|c|}{ Total asperity area } \\
\hline & & & km & & km & & $\mathrm{km}^{2}$ & & $\mathrm{~m}$ & & $\mathrm{~m}$ & & $\mathrm{~km}^{2}$ & & /area & \\
\hline Kubo et al. (2016) & $5.3 \mathrm{E}+19$ & $4.4 \mathrm{E}+19$ & $46.9^{c}$ & 56 & $19.8^{b}$ & 24 & $930^{c}$ & 1344 & $1.66^{c}$ & 1.23 & $4.95^{c}$ & 4.55 & $178^{c}$ & 260 & 0.19 & 0.19 \\
\hline Asano K, Iwata T (2016) & $4.5 E+19$ & & & 42 & & 18 & & 756 & & 1.87 & & 5.13 & & 136 & & 0.18 \\
\hline Yoshida et al. (2016) & $4.8 \mathrm{E}+19$ & & & $44^{b}$ & & 18 & & 792 & & 1.98 & & 5.18 & & 160 & & 0.20 \\
\hline
\end{tabular}

\footnotetext{
a Seismic moment obtained from inversion results

b Fault length and width are trimmed following the criterion of Somerville et al. (1999)

c Logarithm averages of the three models
} 


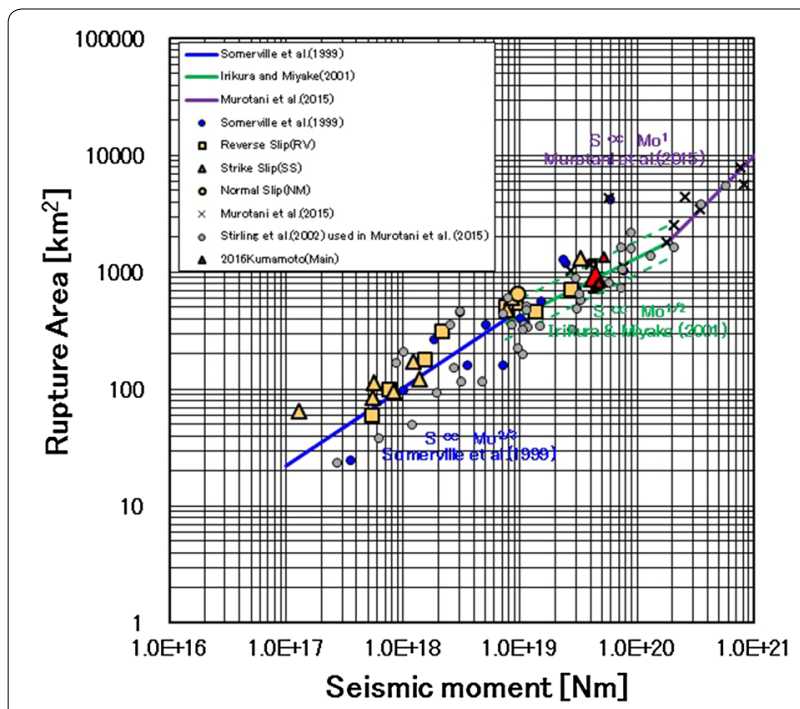

Fig. 2 Relationship between rupture area and seismic moment for crustal earthquakes. Two broken green lines indicate one SD $(\sigma=0.14)$ for inland crustal earthquakes in Japan. The large red triangle represents the logarithmic average of the rupture areas of the three models for the 2016 Kumamoto earthquake $\left(M_{w} 7.0\right)$ shown in Table 1. The small red triangles indicate the rupture areas from individual models

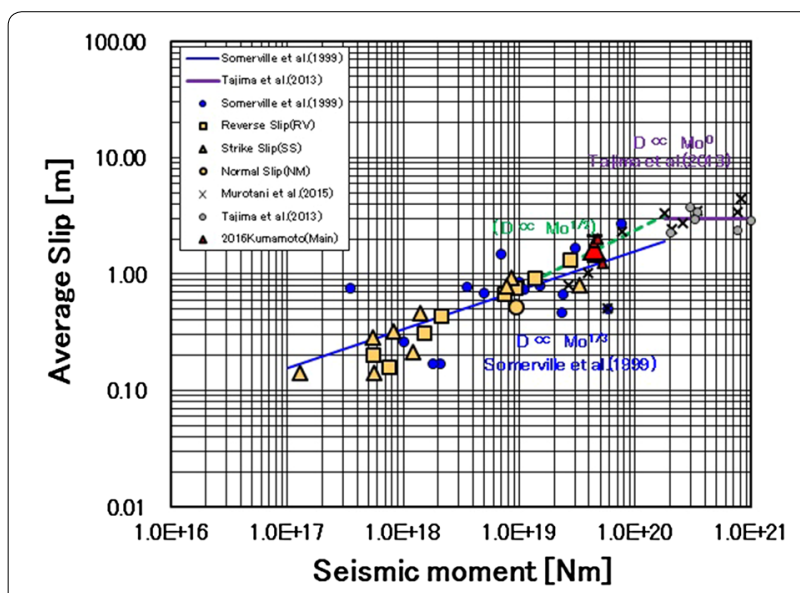

Fig. 3 Relationship between average slip area and seismic moment for crustal earthquakes. The large red triangle represents the 2016 Kumamoto earthquake $\left(M_{w} 7.0\right)$. The small red triangles indicate the average slips from individual models shown in Table 1

Asperities are regions that have large slip relative to the average slip in the rupture area (Somerville et al. 1999). These asperity areas, as well as the total rupture area, scale with the seismic moment (Fig. 4). The majority of strong-motion records are reproduced with motions generated from asperities. Contributions from the background area of the characterized source model are not important for strong-motion records but must match

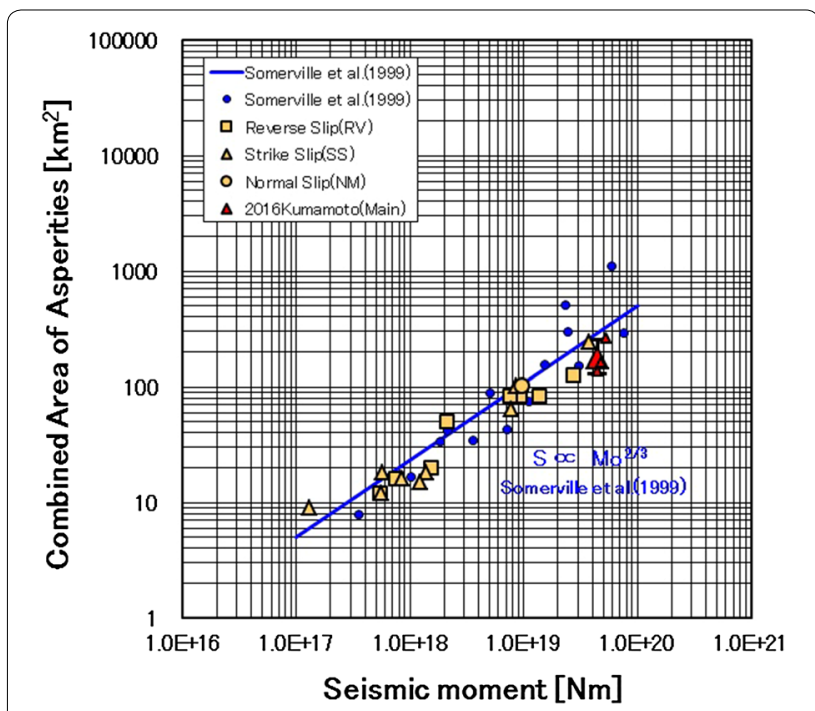

Fig. 4 Relationship between the combined area of the asperities and the seismic moment for crustal earthquakes. The large red triangle represents the 2016 Kumamoto earthquake $\left(M_{w} 7.0\right)$. The small red triangles indicate the combined areas from individual models shown in Table 1

long-period motions, including the seismic moment (Miyake et al. 2003; Irikura and Miyake 2011).

Therefore, the synthetic ground motions were calculated with the assumption that ground motions were only generated within the SMGAs, which were redefined based on asperity location and area information (Kamae and Irikura 1998; Miyake et al. 2003). The synthetic ground motions from the SMGAs approximately agree with the observed motions (Kamae and Irikura 1998). For the 1995 Hyogo-ken Nanbu earthquake $\left(M_{w} 6.9\right)$, which was nearly the same size as the 2016 Kumamoto earthquake, the period range available for the SMGA model is shorter than $5 \mathrm{~s}$. We found that for crustal earthquakes, the SMGAs coincide approximately with asperity area (Miyake et al. 2003). Therefore, this characterized source model consisting of SMGAs with large stress parameters and a background area with a zero stress parameter is called the SMGA source model.

We estimated the SMGA source model by comparing the synthetic and observed ground motions from the 2016 Kumamoto earthquake. Whether the SMGAs coincide with the asperity areas of large slip is discussed below. The empirical Green's function (EGF) method was used to simulate strong ground motions to avoid difficulty in obtaining accurate velocity structures.

First, we constructed a characterized source model with the SMGAs based on the slip distribution model of Yoshida et al. (2016). This model consists of four segments, 


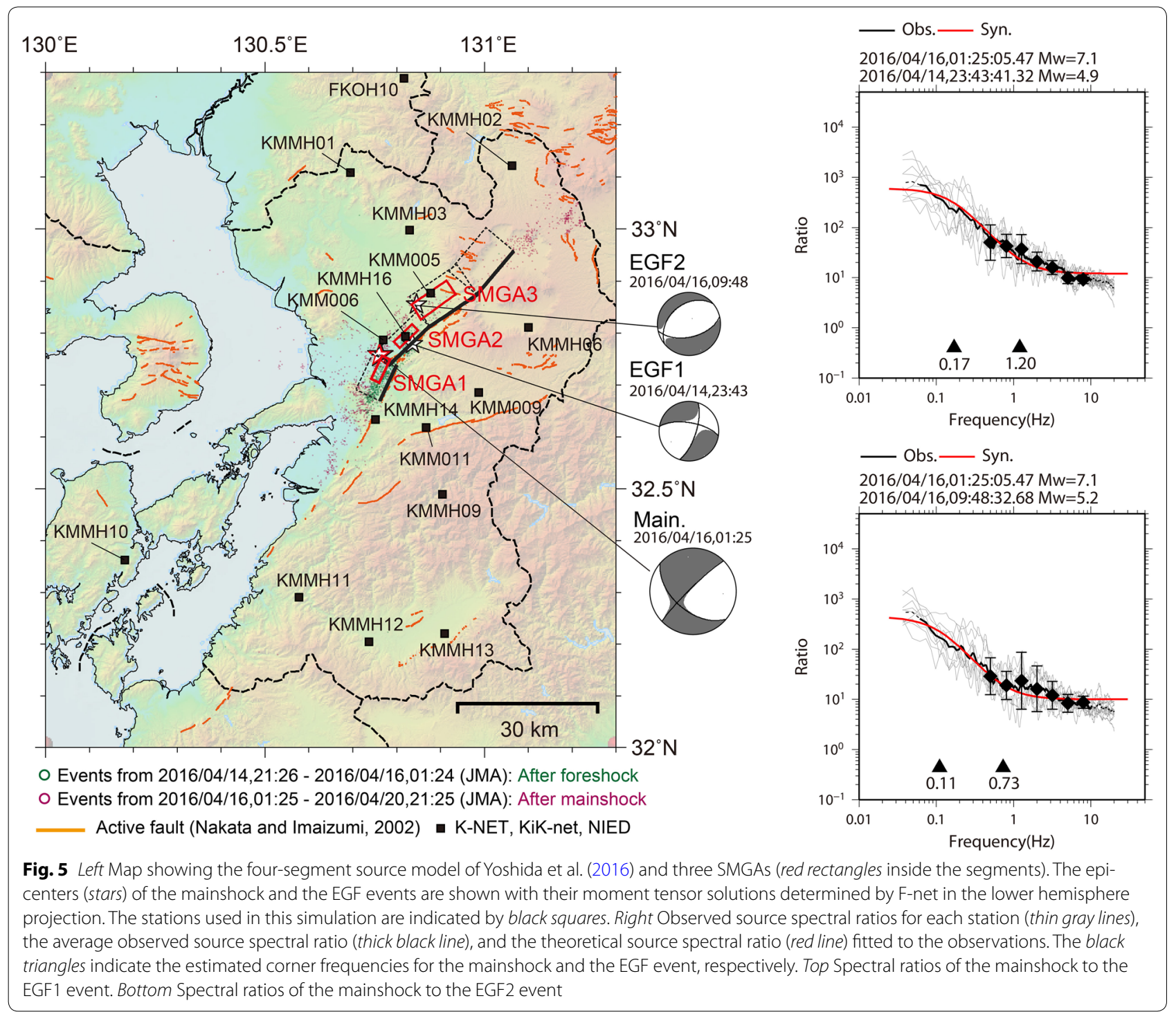

as shown in Fig. 1a. As shown in the left panel of Fig. 5, we assumed an SMGA in each segment, except the northeast segment (Seg. 4) of the Futagawa fault zone located near the Mount Aso volcano. The northeast segment generated relatively small peak-moment-rate motions compared to the other three segments (Fig. 6, lower).

The EGF events whose records are used as the EGFs were carefully selected to have hypocenters close to the SMGAs with radiation characteristics nearly identical to those of the target events. We selected records of a foreshock $\left(M_{w} 4.9\right.$, EGF1) and an aftershock $\left(M_{w} 5.1\right.$, EGF2) for the EGFs. The EGF1 event occurred very close to SMGA1 and inside SMGA2, with predominant strikeslip faulting similar to the focal mechanism of the mainshock (Fig. 5, left). Therefore, the records of EGF1 were used as the EGFs for SMGA1 and SMGA2. However, the
EGF2 event occurred very close to SMGA3, with strikeslip faulting and a normal-faulting component (Fig. 5, left) similar to the focal mechanism around SMGA3 during the mainshock. Therefore, we selected the records of EGF2 for the EGFs for SMGA3.

We calculated the spectral ratios between the mainshock and the EGF events to estimate the corner frequency of the EGF events (Fig. 5, right). The source areas and the stress parameters of these events were estimated from the seismic moment and the corner frequency using Brune's $(1970,1971)$ formula. The parameters of these events are listed in Table 2. We found that the records of the EGF events were reliable within the frequency range of $0.2-10 \mathrm{~Hz}$ because the spectral ratios follow the omega-squared model in this frequency range and deviate from it below $0.2 \mathrm{~Hz}$ and beyond $10 \mathrm{~Hz}$. 

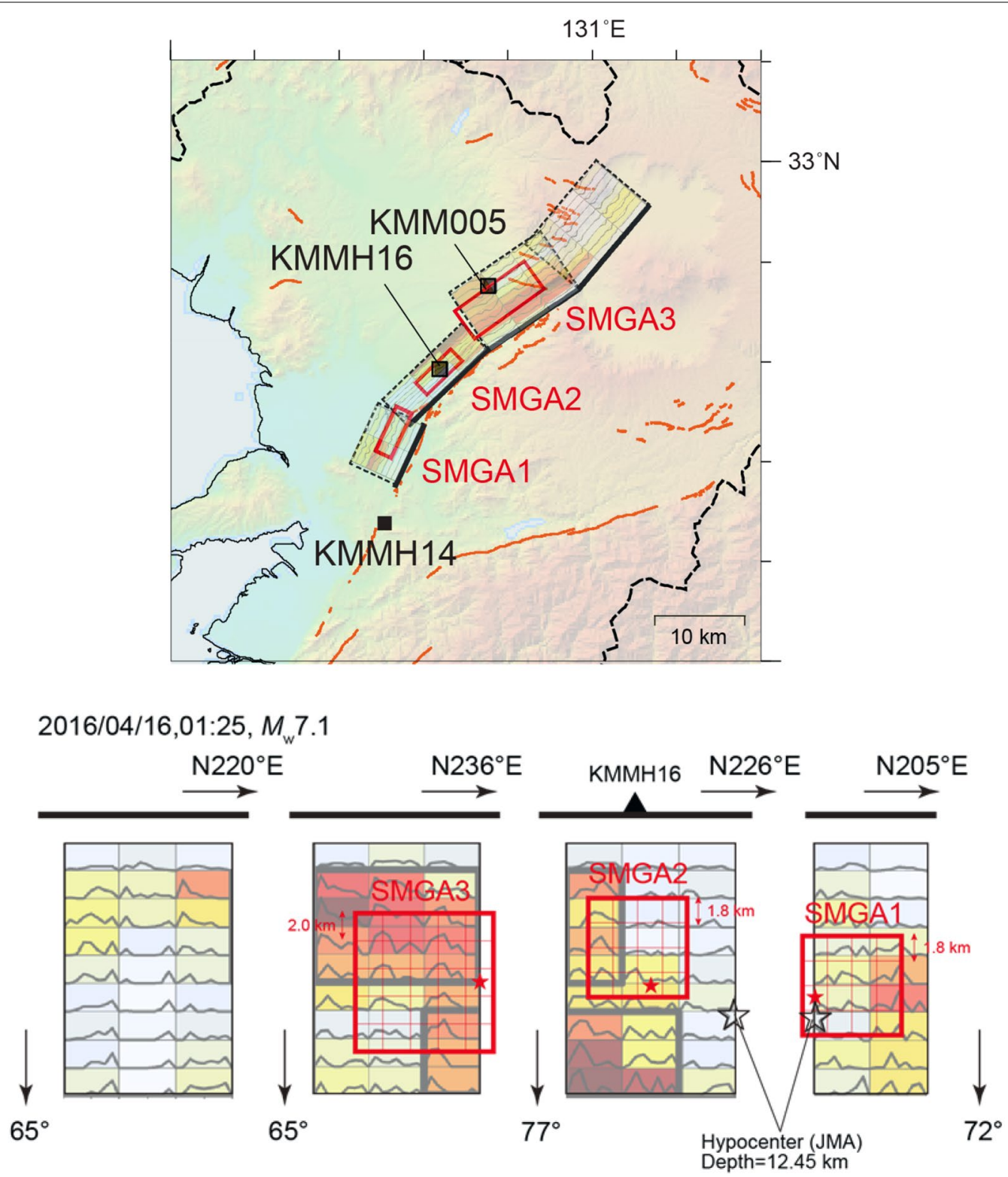

Fig. 6 Top Map view of the four-segment source model of Yoshida et al. (2016) and the SMGA model. Bottom The SMGA model projected on the fault plane with the distributions of the peak-moment rates (warm colors) and the moment-rate functions (solid lines in subfaults) on the four segments. The hypocenter of the mainshock (large white star) and the rupture starting point (small red star) of each SMGA are indicated

Each SMGA area was divided into $\mathrm{N} \times \mathrm{N}$ subfaults, the areas of which were taken to be equal to the fault area of each EGF event. The location and size of each SMGA and the rupture starting point, rupture velocity and slip duration inside each SMGA were estimated based on comparison of the timing, shape and amplitude of the synthetic and observed waveforms through trial and error.

A map view of the three SMGAs is shown in the upper panel of Fig. 6 . The fit between the synthetic and observed waveforms in this analysis was judged via visual inspection, because the parameters for the three SMGAs are by necessity optimized simultaneously. The three best-fit SMGAs in this analysis are plotted in the lower panel of Fig. 6, with the peak moment-rate distributions drawn in warm colors on the three segments of Yoshida et al. (2016). The source parameters of the SMGAs are listed in Table 3. The observed and synthetic ground motions are shown in Fig. $7 \mathrm{a}-\mathrm{c}$. The agreement is satisfactory for acceleration, velocity, and displacement at most of the stations. 
Table 2 Source parameters of the EGF1 event (foreshock) and the EGF2 event (aftershock)

\begin{tabular}{lll}
\hline & EGF1 & EGF2 \\
\hline${\text { Origin time }(J S T)^{\mathrm{a}}}_{\text {Depth }(\mathrm{km})^{\mathrm{a}}}$ & $2016 / 04 / 14,23: 43$ & $2016 / 04 / 16,09: 48$ \\
Seismic moment $(\mathrm{N} \mathrm{m})^{\mathrm{b}}$ & 14.2 & 15.9 \\
$M_{\mathrm{w}}^{\mathrm{b}}$ & $2.71 \times 10^{16}$ & $6.27 \times 10^{16}$ \\
${\text { Strike, dip, rake }(\mathrm{deg} .)^{\mathrm{b}}}$ & 4.9 & 5.2 \\
$V_{\mathrm{s}}(\mathrm{km} / \mathrm{s})^{\mathrm{c}}$ & $279,67,-22$ & $230,38,-112$ \\
Corner frequency $(\mathrm{Hz})$ & 3.4 & 3.4 \\
Fault length $(\mathrm{km})$ & 1.20 & 0.73 \\
Stress parameter $(\mathrm{MPa})$ & 1.86 & 3.01 \\
\hline
\end{tabular}

${ }^{a}$ JMA, ${ }^{b}$ F-net, ${ }^{c}$ J-SHISV2: Fujiwara et al. (2012)

Table 3 Parameters of the three-SMGA model based on the slip distribution of Yoshida et al. (2016)

\begin{tabular}{llll}
\hline & SMGA1 & SMGA2 & SMGA3 \\
\hline Area $\left(\mathrm{km}^{2}\right)$ & 51.8 & 51.8 & 100.0 \\
Seismic moment $(\mathrm{N} \mathrm{m})$ & $2.08 \times 10^{18}$ & $2.08 \times 10^{18}$ & $5.49 \times 10^{18}$ \\
Rise time $(\mathrm{s})$ & 0.6 & 0.6 & 0.6 \\
Stress parameter $(\mathrm{MPa})$ & 13.6 & 13.6 & 13.4 \\
Rupture velocity $(\mathrm{m} / \mathrm{s})$ & 2.8 & 2.8 & 2.8 \\
\hline
\end{tabular}

Next, we constructed a characterized source model with the SMGAs based on the single fault plane model along the Futagawa fault zone estimated by Kubo et al. (2016) to be the source fault of the 2016 Kumamoto earthquake. It is preferable to use simpler fault geometry to predict strong ground motions for future earthquakes if synthetic motions that fit the observed motions reasonably well can be obtained.

We formulated a simplified SMGA model where "a single SMGA" was put into the single fault plane proposed by Kubo et al. (2016) based on the slip distribution. For the EGFs, we selected records of a foreshock $\left(M_{w} 4.4\right)$ that had nearly the same focal mechanism as the mainshock and that occurred inside the SMGA. We also calculated the spectral ratios between the mainshock and the EGF event to estimate the corner frequency of the EGF event, the source area, and the stress parameter. The source parameters of this event are listed in Table 4. The reliable frequency range in this case was $0.3-10 \mathrm{~Hz}$.

The entire assumed fault plane and the SMGA are shown in Fig. 8 with the observed stations used for this analysis. The best-fit characterized source model to simulate ground motions using the EGF method was determined through choosing the starting point, rupture velocity, and slip duration by comparing the observed and synthetic waveforms. The criterion for the best-fit is minimizing the residuals between the observed and synthetic waveforms using the fitness function given by Miyake et al. (1999). The residual is defined as the sum of the squared residuals of the displacement waveforms and acceleration envelopes.

The best-fit SMGA to the observed waveforms is shown in Fig. 9 with the slip distribution reported by Kubo et al. (2016) indicated with warm colors. The parameters of the SMGA used for the simulation, such as length, width, rise time, seismic moment, and stress parameter, are listed in Table 5. The synthetic motions agree with the observed motions for acceleration, velocity, and displacement, as shown in Fig. 10, including at KMMH16 (KiKnet Mashiki), KMMH14 (KiK-net Toyono) and KMM005 (K-NET Ohzu), which are located very near the source fault.

The location of the SMGA indicated in Fig. 9 coincides with a large slip area deeper than $5 \mathrm{~km}$ but does not correspond to a near-surface slip area in the northeast of the fault plane, which is consistent with the SMGA model in the upper panel of Fig. 6 based on the slip distributions of Yoshida et al. (2016). The inverted slip-velocity time functions in the near-surface areas in the lower panel of Fig. 6 have motions longer than 3 s. Therefore, the ground motions generated by the large near-surface slip may have had little influence on the strong ground motions shorter than $3 \mathrm{~s}$. This finding may explain why there were no SMGAs in the northeast area of the fault plane shown in the upper panel of Fig. 6 based on the model of Yoshida et al. (2016) or in Fig. 9 based on the model of Kubo et al. (2016).

The combined area of the three SMGAs from the foursegment model of Yoshida et al. (2016) is about $204 \mathrm{~km}^{2}$. The SMGA from the single fault plane model of Kubo et al. (2016) is $17.3 \mathrm{~km}$ in length and $13.0 \mathrm{~km}$ in width, for an area of $224.9 \mathrm{~km}^{2}$. Conversely, the asperity area based on the inverted heterogeneous slip distributions, i.e., the logarithmic average of the three models in Table 1, is about $180 \mathrm{~km}^{2}$. Therefore, we found that both the combined area of the three SMGAs in Fig. 6 and the area of the single SMGA in Fig. 9, which were obtained using different forward modeling approaches, are nearly the same as the asperity area determined based on the slip distributions from waveform inversion using the strongmotion data.

The SMGAs in the upper panel of Fig. 6 obtained based on the four-segments source model of Yoshida et al. (2016) do not always coincide with the SMGA in Fig. 9 from the single segment source model of Kubo et al. (2016). However, the locations and the combined area of the three SMGAs in Fig. 6 are nearly the same as those of the SMGA in Fig. 9. The synthetic ground motions for acceleration, velocity, and displacement shown in Fig. 7 


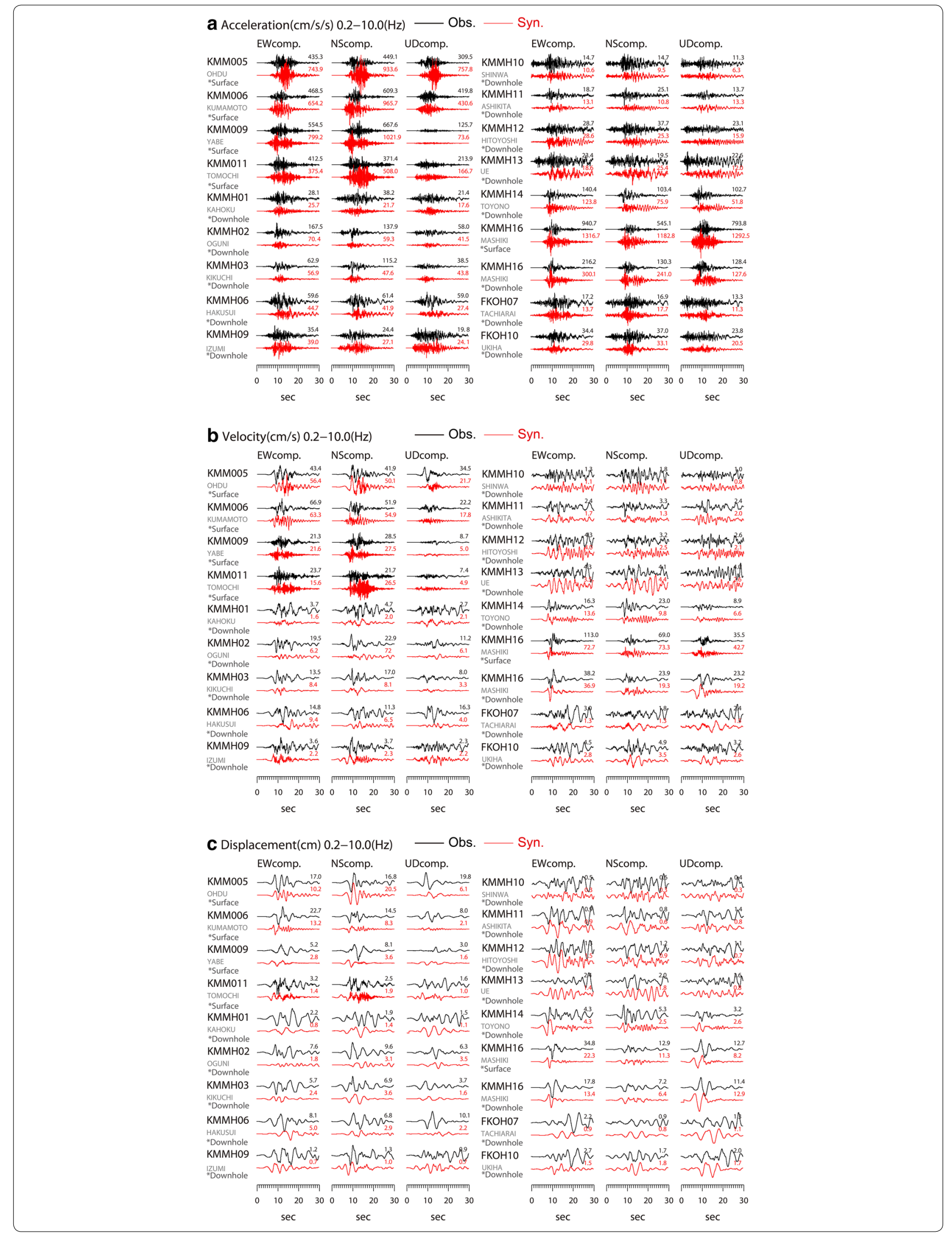


(See figure on previous page.)

Fig. 7 Comparisons of the observed (black) and synthetic (red) ground motions of three components (east-west, north-south, and up-down). The available frequency range is from 0.2 to $10 \mathrm{~Hz}$. a Acceleration in $\mathrm{cm} / \mathrm{s}^{2}, \mathbf{b}$ velocity in $\mathrm{cm} / \mathrm{s}$ and $\mathbf{c}$ displacement in $\mathrm{cm}$. The numbers in each trace indicate the maximum amplitude

have almost the same amplitudes as those in Fig. 10. These findings indicate that this method of estimating ground motion based on SMGA models is robust because the simulation results do not differ greatly between these different SMGA models.

\section{Conclusions}

A three-stage scaling model of the source parameters for crustal earthquakes in Japan has previously been

\section{Table 4 Source parameters of the EGF event (foreshock)}

\begin{tabular}{ll}
\hline${\text { Origin time }(\mathbf{J S T})^{\mathbf{a}}}$ & $\mathbf{2 0 1 6 / 0 4 / 1 5 , ~ 0 : 5 0}$ \\
\hline Depth $(\mathrm{km})^{\mathrm{a}}$ & 13.4 \\
Seismic moment $(\mathrm{N} \mathrm{m})^{\mathrm{b}}$ & $3.86 \times 10^{15}$ \\
$M_{\mathrm{w}}^{\mathrm{b}}$ & 4.4 \\
Strike, dip, rake (deg. $)^{\mathrm{b}}$ & $209,70,177$ \\
$V_{\mathrm{s}}(\mathrm{km} / \mathrm{s})^{\mathrm{c}}$ & 3.4 \\
Corner frequency (Hz) & 1.55 \\
Fault length $(\mathrm{km})$ & 1.44 \\
Stress parameter $(\mathrm{MPa})$ & 3.16 \\
\hline
\end{tabular}

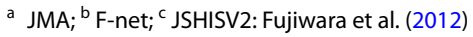

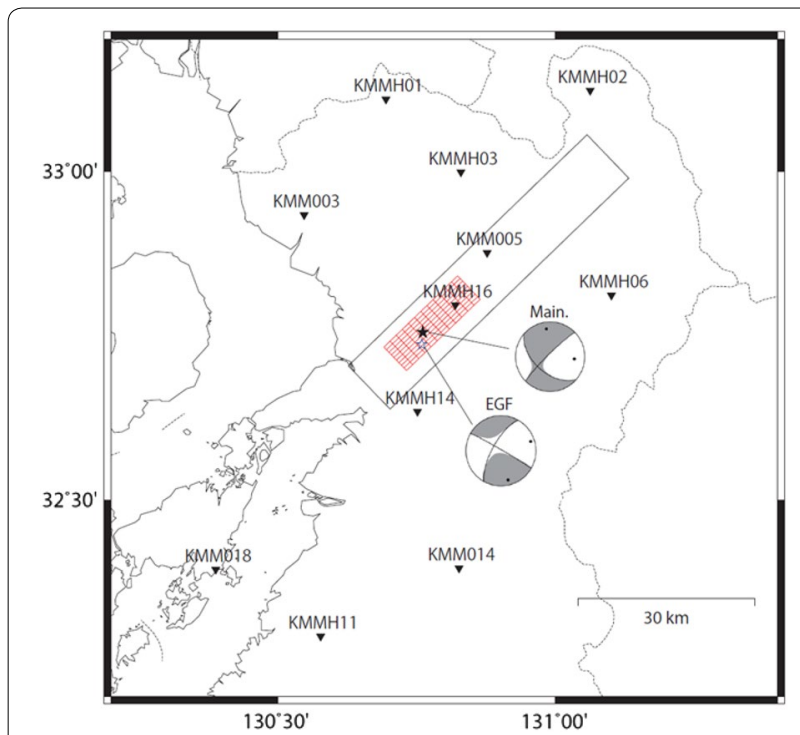

Fig. 8 Map showing the entire fault plane along the Futagawa fault zone (Kubo et al. 2016) and the SMGA model for the strong motion estimation. The epicenters (stars) of the mainshock and the EGF event $\left(M_{w} 4.4,2016 / 04 / 15\right)$ are shown with their moment tensor solutions determined by F-net in the lower hemisphere projection. The stations used in this simulation are indicated by downward-pointing triangles constructed by Irikura and Miyake (2001) and Murotani et al. (2015) based on source parameters from the results of waveform inversion with strong-motion data. Miyakoshi et al. (2015) examined the validity of these scaling relationships using waveform inversion results for 18 crustal earthquakes $\left(M_{w} 5.4-6.9\right)$ in Japan since the 1995 Hyogo-ken Nanbu earthquake. The 2016 Kumamoto earthquake, with $M_{w} 7.0$, is one of the largest earthquakes in this interval of time, and the associated strong ground motions were recorded by dense and accurate strong-motion networks. The main purpose of this study was to validate whether the scaling relationships of the source parameters for crustal

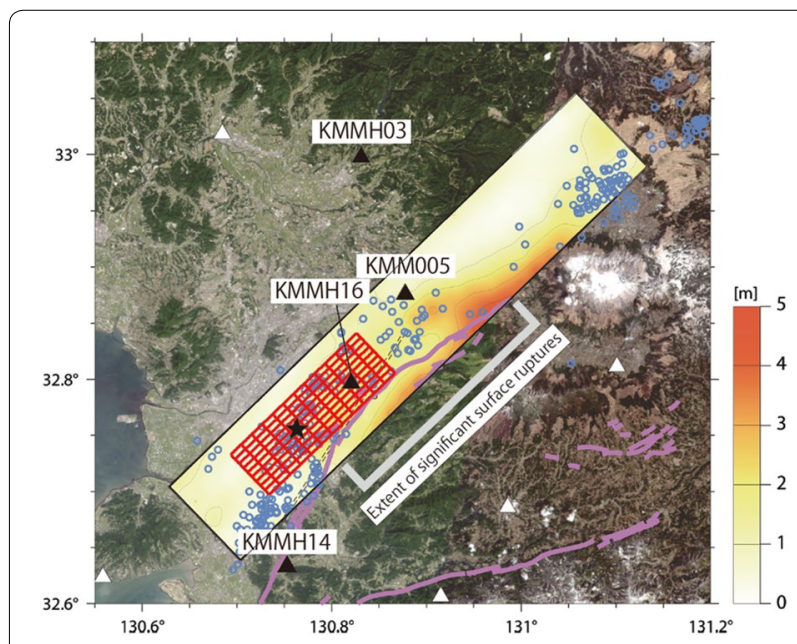

Fig. 9 Map projection of the slip distribution of Kubo et al. (2016) and the best-fit model of the SMGA (red rectangle). The locations of active faults are indicated by purple lines and aftershocks are marked by blue circles. Background map was made using GSI Maps from the Geospatial Information Authority of Japan (http://maps.gsi.go.jp) This figure is modified from Kubo et al. (2016)

Table 5 Parameters of the single SMGA model based on the slip distribution of Kubo et al. (2016)

\begin{tabular}{ll}
\hline & SMGA \\
\hline Area $\left(\mathrm{km}^{2}\right)$ & 224.9 \\
Seismic moment $(\mathrm{N} \mathrm{m})$ & $1.83 \times 10^{19}$ \\
Rise time $(\mathrm{s})$ & 0.8 \\
Stress parameter $(\mathrm{MPa})$ & 13.9 \\
Rupture velocity $(\mathrm{km} / \mathrm{s})$ & 2.8 \\
\hline
\end{tabular}


a Acceleration $(\mathrm{cm} / \mathrm{s} / \mathrm{s})$
EWcomp.
$0.3-10.0(\mathrm{~Hz})$
NScomp. UDcomp

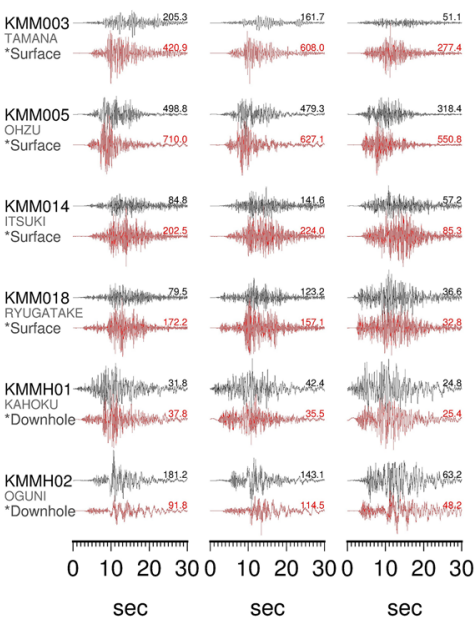

$\mathrm{sec}$

$\sec$

$\sec$

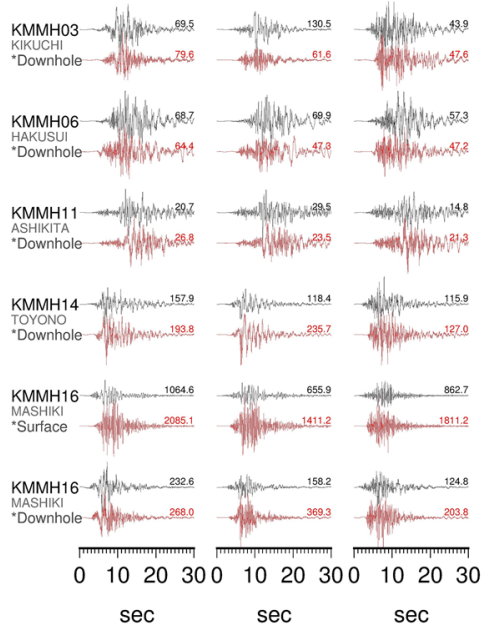

b Velocity $(\mathrm{cm} / \mathrm{s}) 0.3-10.0(\mathrm{~Hz})$

EWcomp. NScomp. UDcomp.

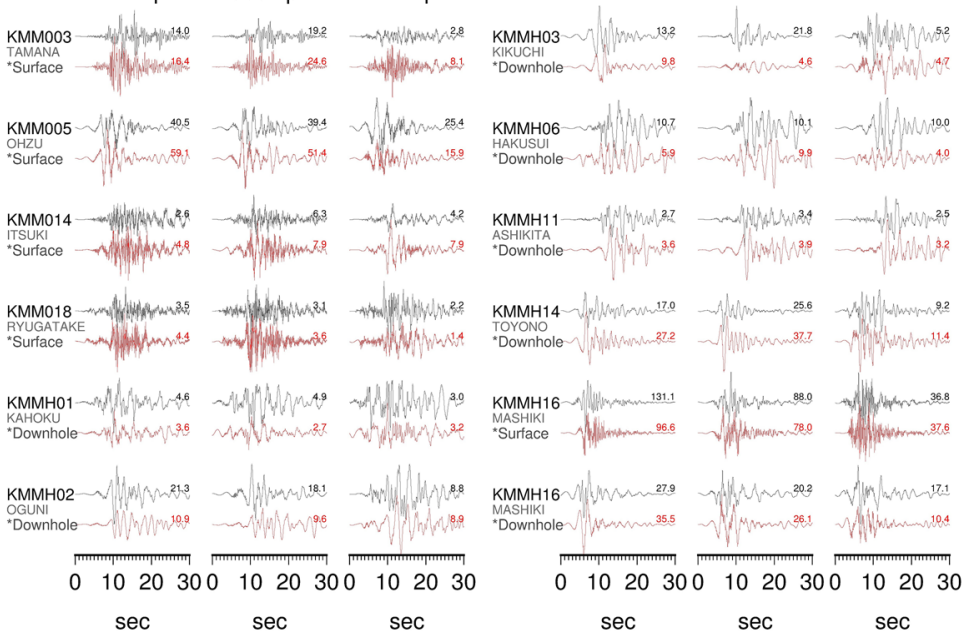

C Displacement $(\mathrm{cm})$ 0.3-10.0(Hz)

EWcomp. NScomp. UDcomp.

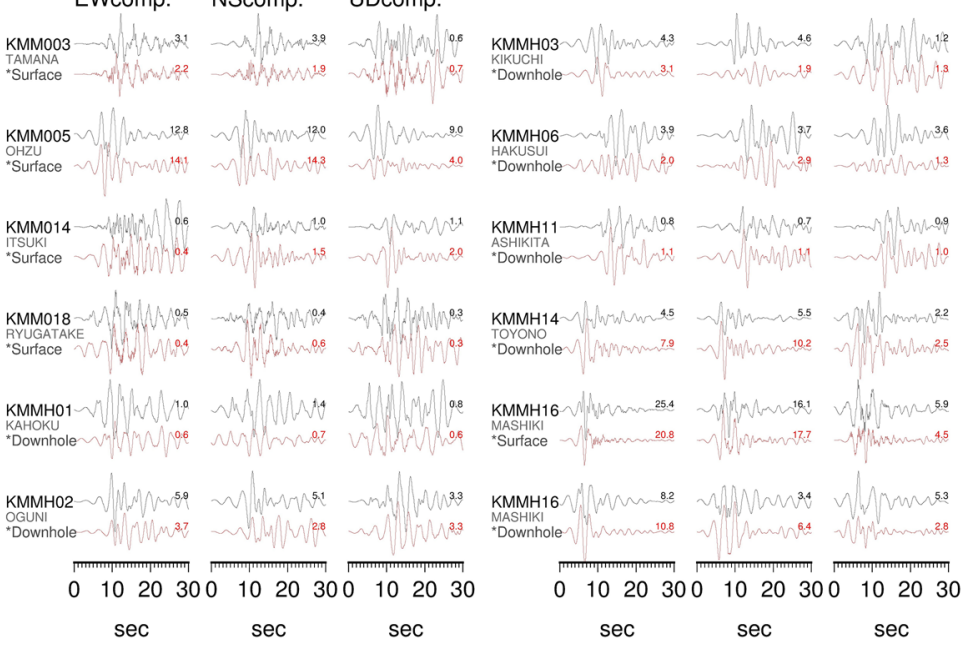


(See figure on previous page.)

Fig. 10 Comparison of the observed (black) and synthetic (red) ground motions of three components (east-west, north-south, and up-down). The available frequency range is from 0.3 to $10 \mathrm{~Hz}$. a Acceleration in $\mathrm{cm} / \mathrm{s}^{2}, \mathbf{b}$ velocity in $\mathrm{cm} / \mathrm{s}$, and $\mathbf{c}$ displacement in $\mathrm{cm}$. The numbers in each trace indicate the maximum amplitude

earthquakes in Japan are applicable to the 2016 Kumamoto earthquake.

We collected slip distributions inverted from strongmotion data of the 2016 Kumamoto earthquake and extracted the rupture area and the asperity area from the waveform inversion results. Without including the 2016 Kumamoto earthquake, the standard deviation of the second stage was calculated to be $\sigma=0.14$. We confirmed that the scaling relationship between the rupture area $S$ and the seismic moment $M_{0}$ is applicable to the second stage for the 2016 Kumamoto earthquake within one standard deviation. We also found that the average slip $D$ increases proportionally with $M_{0}^{1 / 2}$ in the second-stage scaling, including for the 2016 Kumamoto earthquake.

Furthermore, we simulated the strong ground motions of the 2016 Kumamoto earthquake using the characterized source model with an SMGA in a fault segment using the EGF method. The synthetic motions obtained with the EGF method agree with the observed motions with respect to acceleration, velocity, and displacement in the frequency range from 0.3 to $10 \mathrm{~Hz}$.

Therefore, we conclude that the scaling relationships of the source parameters are appropriate to reproduce the strong ground motions of the 2016 Kumamoto earthquake.

\section{Authors' contributions}

KI designed the study and drafted the manuscript. KM and KK analyzed the source scaling. $\mathrm{KY}, \mathrm{KS}$, and SK analyzed the strong-motion data. HM participated in the discussion and interpretation. All authors read and approved the final manuscript.

\section{Author details}

' Disaster Prevention Research Center, Aichi Institute of Technology, 1247 Yachigusa, Yakusa-cho, Toyota 470-0392, Aichi, Japan. ${ }^{2}$ Geo-Research Institute, Osaka, Japan. ${ }^{3}$ Research Reactor Institute, Kyoto University, Osaka, Japan.

${ }^{4}$ Aichi Institute of Technology, Aichi, Japan. ${ }^{5}$ Center for Integrated Disaster Information Research, Interfaculty Initiative in Information Studies/Earthquake Research Institute, The University of Tokyo, Tokyo, Japan.

\section{Acknowledgements}

We express our gratitude to the National Research Institute for Earth Science and Disaster Resilience (NIED) for providing K-NET and KiK-net data. We acknowledge valuable comments from Haruo Horikawa and two anonymous reviewers. This work was supported in part by Aichi Institute of Technology.

\section{Competing interests}

The authors declare that they have no competing interests.

Received: 11 August 2016 Accepted: 7 December 2016

Published online: 03 January 2017

\section{References}

Asano K, Iwata T (2016) Rupture process of the MJ 7.3 earthquake of the (2016) Kumamoto earthquake sequences. Earth Planets Space 68:147. doi:10.1186/s40623-016-0519-9

Brune JN (1970) Tectonic stress and the spectra of seismic shear waves from earthquakes. J Geophys Res 75:4997-5009. doi:10.1029/JB075i026p04997

Brune JN (1971) Correction. J Geophys Res 76:5002. doi:10.1029/ JB076i020p05002

Fujiwara H, Kawai S, Aoi S, Morikawa N, Senna S, Azuma H, Ooi M, Hao XN, Hasegawa K, Maeda T, Iwaki A, Wakamatsu K, Imoto M, Okumura T, Matsuyama H, Narita A (2012) Some improvements of seismic hazard assessment based on the 2011 Tohoku earthquake. In: Technical note 379, National Research Institute for Earth Science and Disaster Prevention, Tsukuba, Japan (in Japanese)

Fukuyama E, Ishida M, Dreger DS, Kawai H (1998) Automated seismic moment tensor determination by using on-line broadband seismic waveforms. J Seismol Soc Jpn 51:149-156 (in Japanese with English abstract)

Headquarters for Earthquake Research Promotion (2016) Evaluation of the 2016 Kumamoto Earthquakes. http://www.jishin.go.jp/main/ chousa/16may kumamoto/index-e.htm

Irikura K, Miyake H (2001) Prediction of strong ground motions for scenario earthquake. J Geogr 110:849-875 (in Japanese with English abstract)

Irikura K, Miyake H (2011) Recipe for predicting strong ground motion from crustal earthquake scenario. Pure Appl Geophys 168:85-104. doi:10.1007/ s00024-010-0150-9

Kamae K, Irikura K (1998) Rupture process of the 1995 Hyogo-ken Nanbu earthquake and simulation of near-source ground motion. Bull Seismol Soc Am 88:400-412

Kanamori H, Anderson DL (1975) Theoretical basis of some empirical relations in seismology. Bull Seismol Soc Am 65:1073-1095

Kubo H, Suzuki W, Aoi S, Sekiguchi H (2016) Rupture process of the M 7.3, April 16, mainshock of the 2016 Kumamoto earthquake obtained from strong-motion data. http://www.kyoshin.bosai.go.jp/kyoshin/topics/ Kumamoto_20160416/inversion_v2/index_en.html

Miyake H, Iwata T, Irikura K (1999) Strong ground motion simulation and source modeling of the Kagoshima-ken Hokuseibu earthquake of March 26 ( $\left.M_{\text {JMA }} 6.5\right)$ and May 13 (M MMA 6.3), 1997, using empirical Green's function method. J Seism Soc Jpn (Zisin) 51:431-442 (in Japanese with English abstract)

Miyake H, Iwata T, Irikura K (2003) Source characterization for broadband ground-motion simulation: kinematic heterogeneous source model and strong motion generation area. Bull Seismol Soc Am 93:2531-2545

Miyakoshi K, Kagawa T, Sekiguchi H, Iwata T, Irikura K (2000) Source characterization of inland earthquakes in Japan using source inversion results. In: Proceedings of the 12 th world conference on earthquake engineering, Auckland, September 2000

Miyakoshi K, Irikura K, Kamae K (2015) Re-examination of scaling relationships of source parameters of the inland crustal earthquakes in Japan based on the waveform inversion of strong motion data. J Jpn Assoc Earthq Eng 15(7):141-156 (in Japanese with English abstract)

Murotani S, Matsushima S, Azuma T, Irikura K, Kitagawa S (2015) Scaling relations of source parameters of earthquakes occurring on inland crustal mega-fault systems. Pure Appl Geophys 172:1371-1381. doi:10.1007/ s00024-014-1010-9

Nakata T, Imaizumi T (eds) (2002) Digital active fault map of Japan. University of Tokyo Press, Tokyo

Shimazaki K (1986) Small and large earthquake: the effects of thickness of seismogenic layer and the free surface. In: Das S, Boatwright J, Scholz CH (ed) Earthquake source mechanics, AGU monograph 37, Maurice Ewing Ser. 6, pp 209-216 
Somerville P, Irikura K, Graves R, Sawada S, Wald D, Abrahamson N, Iwasaki Y, Kagawa T, Smith N, Kowada A (1999) Characterizing crustal earthquake slip models for the prediction of strong ground motion. Seismol Res Lett 70:59-80

Stirling M, Rhoades D, Berryman K (2002) Comparison of earthquake scaling relations derived from data of the instrumental and preinstrumental era. Bull Seismol Soc Am 92:812-830

Stirling M, Goded T, Berryman K, Litchfield N (2013) Selection of earthquake scaling relationships for seismic-hazard analysis. Bull Seismol Soc Am 103:2993-3011
Tajima R, Matsumoto Y, Si H, Irikura K (2013) Comparative study on scaling relations of source parameters for great earthquakes in inland crusts and on subducting plate boundaries. J Seismol Soc Jpn 66:31-45 (in Japanese with English abstract)

Wells DL, Coppersmith KJ (1994) New empirical relationships among magnitude, rupture length, rupture width, rupture area, and surface displacement. Bull Seismol Soc Am 84:974-1002

Yoshida K, Miyakoshi K, Somei K (2016) Kinematic source model of the 2016 Kumamoto earthquake $\left(M_{j} 7.3\right)$ inverted from strong motion records (ver. 2). Fall meeting of 2016 Seismological Society of Japan, S15-P02

\section{Submit your manuscript to a SpringerOpen ${ }^{\circ}$ journal and benefit from:}

- Convenient online submission

- Rigorous peer review

Immediate publication on acceptance

- Open access: articles freely available online

- High visibility within the field

- Retaining the copyright to your article 